\title{
RETOS Y PERSPECTIVAS DE LA GUARDIA NACIONAL EN MÉXICO
}

CHALLENGES AND PROSPECTS OF THE NATIONAL GUARD IN MEXICO

RICARDO ALEXIS UVALLE AGUILERA ${ }^{1}$

RESUMEN: A principios de 2019 fue aprobada en México una reforma constitucional para crear la llamada Guardia Nacional. Además de generar un gran debate mediático y dar lugar a puntos de vista sobre su pertinencia e idoneidad y ser motivo de análisis y críticas, su vigencia enfrenta grandes desafíos de cara a su implementación. Esto es así porque aunado a las dudas sobre su convencionalidad, en el marco del Sistema Interamericano de Derechos Humanos, la forma en que plantea los requisitos de ingreso y permanencia requieren ser estudiados con todo cuidado desde una perspectiva histórica y jurídica. En este sentido, el propósito del presente trabajo es analizar las particularidades y características del diseño institucional de la Guardia, considerando la perspectiva internacional de los derechos humanos y proponer una serie de recomendaciones de cara a su implementación.

Palabras Clave: Guardia Nacional, retos, seguridad, derechos humanos.

ABStract: At the beginning of 2019 a constitutional reform was approved in Mexico to create the so-called National Guard. In addition to generating a great media debate and giving rise to points of view on its relevance and suitability and being a reason for analysis and criticism, its validity faces great challenges in terms of its implementation. This is because, combined with doubts about its conventionality, within the framework of the Inter-American Human Rights System, the way in which it sets forth the requirements for entry and permanence requires careful study from a historical and legal perspective. In this sense, the purpose of this paper is to analyze the particularities and characteristics of the institutional design of the Guardia, considering the international perspective of human rights and propose a series of recommendations for its implementation.

\footnotetext{
${ }^{1}$ Estudiante de Doctorado en el Instituto de Investigaciones Jurídicas de la UNAM. Correo: <ruvalle89@gmail.com>
} 
KEYWORDS: Nacional Guard, challenges, security, human rights.

SUMARIO: I. Introducción. II. Diseño institucional de la Guardia Nacional III. Perspectiva Internacional de los Derechos Humanos. IV. Conclusiones. V. Fuentes.

\section{INTRODUCCIÓN}

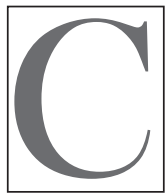

omo parte de su estrategia de seguridad, el Presidente Andrés Manuel López Obrador ha impulsado la creación de una Guardia Nacional responsable de la política de seguridad del Estado

mexicano. En su diseño se plantea la coexistencia de las policías Naval, Militar y Federal, así como una convocatoria abierta para que jóvenes que cumplan con determinados requisitos se puedan alistar en la misma y formen parte del cuerpo que habrá de garantizar la función principal de todo Estado moderno: seguridad para sus habitantes. En este sentido, cabe hacer notar que si bien la forma en que se plantea la creación de la misma y los matices que habrán de definir su implementación, pueden resultar novedosos al público en general, la realidad es que la figura tiene ciento noventa y cinco años en el texto constitucional. La forma en que se concibió en aquél tiempo dista mucho de cómo se planea su estructura y funcionamiento en la actualidad. La historia nos arroja que en realidad a México le ha importado generar cuerpos de seguridad responsables de garantizar la paz social en el ámbito interno, así como defender la soberanía nacional ante los embates de fuerzas extranjeras. Veamos a continuación, una serie de antecedentes históricos relacionados con esta figura, que si bien en días recientes ha generado gran cantidad de comentarios, análisis y asombro, en realidad tiene mucho tiempo en el texto constitucional, aunque la connotación que se le ha dado es diametralmente distinta a la naturaleza jurídica con la que fue creada. 
De acuerdo con el profesor Jesús García Solano, como antecedente histórico más remoto de la figura de la Guardia Nacional, debe señalarse la llamada Milicia Cívica, la cual, estaba conformada por los ciudadanos armados en defensa de su región; es decir, fue el máximo símbolo de defensa interna. Este primer esbozo de Guardia Nacional surgió con las Cortes de Cádiz y fue reglamentada en 1822, cuando el Congreso Constituyente emitió el Reglamento Provisional Político del Imperio Mexicano. ${ }^{2} \mathrm{Al}$ respecto cabe señalar que aun cuando diversos tratadistas no consideran a esta constitución histórica como parte de los textos constitucionales de México, por haber sido aprobada antes de la Declaración de Independencia, es menester para nuestro objeto de estudio, considerarla como un antecedente primigenio de la figura que analizamos.

Dicho reglamento señalaba que "se organizará la fuerza pública hasta el estado en que el Emperador la juzgue conveniente”; así mismo, retoma los postulados de Cádiz y establece que "ningún mexicano, excepto los eclesiásticos, puede excusarse del servicio militar, siempre que la patria necesite de sus brazos para su defensa y conservación". ${ }^{3}$ No obstante, para hacer vigente y eficaz este precepto, previamente el Soberano Congreso Constituyente Mexicano decretó, el 3 de agosto de 1822, el Reglamento Provisional para la Milicia Cívica, en el que se establece como norma general que esta fuerza militar. ${ }^{4}$ Se compondría, en este sentido, "de todos los ciudadanos de la edad de diez y ocho a cincuenta años, excepto los ordenados in sacris ${ }^{5}$, y los de primera tonsura y órdenes

\footnotetext{
${ }^{2}$ Solano González, Jesús, "La Guardia Nacional”, Aída. Ópera Prima de Derecho Administrativo. Revista de la Asociación Internacional de Derecho Administrativo, México, año 6, Opus No. 12, julio-diciembre 2012, p. 212.

3 Ídem.

${ }^{4}$ Ibidem, p. 213.

${ }^{5}$ Se le denomina así a la comunicación o participación común en las funciones y cosas sagradas de los católicos con los cristianos que no están en plena comunión con
} 
menores, que guarden las prevenciones del santo concilio de Trento, y último concordato; los marineros, los simples jornaleros, los que tengan impedimento físico para el manejo de las armas, y los funcionarios públicos civiles y militares, quedando a la voluntad de los exentos que no sean eclesiásticos, entrar a esta milicia, en cuyo caso los jueces de primera instancia y los alcaldes no podrán pasar de simples milicianos mientras sirvan a estos cargos". ${ }^{6}$

Las obligaciones de la milicia cívica, que debía formarse en cada pueblo o ciudad, consistían en:

1. Dar guardia principal en las casas capitulares;

2. Dar patrullas para la seguridad pública, y

3. Defender los hogares de su pueblo contra cualquier enemigo.

4. En caso de ausencia de una fuerza de milicia permanente, la milicia cívica debía: concurrir a las funciones de regocijo; perseguir y aprehender a los desertores y malhechores, así como escoltar a los presos y caudales nacionales conducidos desde su pueblo hasta el inmediato donde hubiera milicia correspondiente. ${ }^{7}$

Otro antecedente lo encontramos en la fracción 20 del artículo 72 de la Constitución Federal de los Estados Unidos Mexicanos de 1824, misma que establecía como facultad del Congreso la de "dar su consentimiento a fin de que el Ejecutivo pueda disponer de la guardia nacional fuera de sus respectivos Estados o Territorios, fijando la fuerza necesaria”. Asimismo, como facultad del Ejecutivo se determinó en la fracción la Iglesia católica. Véase A.S. Sánchez-Gil, Voz Communicatio in sacris, en "Diccionario General de Derecho Canónico”, Pamplona. Visible en: http:/www.collationes.org/ de-documenta-theologica/iure-canonico/item/371-sobre-la-communicatio-in-sacris-antonio-s-s\%C3\%A1nchez-gil [consultado el 9 de junio de 2019]

6 Ídem.

${ }^{7}$ Ibidem, pp. 213-214. 
XX del artículo 85, la de disponer de la guardia nacional para los mismos objetos (que en la fracción anterior relativa a la Fuerza Armada para la seguridad interior y defensa exterior de la federación), "en los términos que previene la fracción 20 del artículo 72 ”. Al respecto, cabe hacer notar que el propósito de la Guardia Nacional consistía en garantizar la seguridad interior y la defensa exterior de la Federación, cuya disposición era una facultad conferida al Ejecutivo, misma que requería aprobación del Congreso para ello, por lo cual su uso estaba debidamente controlado mediante la necesaria conjunción de dos voluntades de órganos de poder estatales: 1) la ejecutiva en su disposición y 2) la legislativa en su aprobación.

Sin embargo, no fue hasta ocho años después que el texto constitucional cobró vigencia en la realidad. Se trató de una institución ligada a la seguridad de los estados. Era a nivel local que se designaba a los jefes del cuerpo y se reclutaba a sus efectivos entre comerciantes, terratenientes, artesanos, jornaleros, vaqueros, etc. Su misión era asegurar el orden local y dar seguridad a la región. Al estallar la guerra con los Estados Unidos, el ejército asumió el control de las Guardas Nacionales estatales y ya no lo devolvió. ${ }^{8}$

A decir de nuestro autor, la Guardia Nacional se creó como tal en 1832, y en 1847 pasó a la jurisdicción de la Secretaría de Guerra. En México tuvo una actuación fundamental y compleja, a veces ambivalente. No siempre fue republicana, sino que se subdividió bajo múltiples liderazgos e ideologías, tanto conservadoras como liberales, todas cambiantes según la coyuntura y oportunidad. Precisamente por ser de adscripción estatal,

\footnotetext{
${ }^{8}$ Meyer, Lorenzo, "Un híbrido con historia”, El Universal, México, 2019, disponible en: https: //www.eluniversal.com.mx/columna/lorenzo-meyer/un-hibrido-con-historia, consultado el 26 de mayo de 2019.
} 
estuvo sujeta a los intereses políticos territoriales. ${ }^{9}$ Es importante señalar que la característica de ser un cuerpo militar se relaciona directamente con la ideología permeada en las estructuras de liderazgo en el estado en cuestión, por lo que los “intereses" que habrían de definir la pauta de actuación de la misma, dependían del tipo de afinidad a las ideologías de los gobernantes que estuvieren en el poder: recordemos las pugnas entre liberales y conservadores, y entre federalistas y centralistas, características del siglo XIX en México.

Durante el periodo comprendido de 1846 a 1847 la situación política de México se caracterizó por incertidumbre e inestabilidad en materia de mantenimiento de la soberanía nacional, pues el territorio nacional había sido ocupado por el ejército norteamericano sin gran resistencia por parte del ejército permanente o de la población. Hubo sendas críticas al Estado de México como a otras entidades por negarse a prestar el auxilio que demandaba la capital de la república. ${ }^{10}$ Durante la guerra de intervención de los Estados Unidos en México, Mariano Otero resaltó el valor de la Guardia Nacional y demandó que no estuviera sujeta a los gobernadores sino a la defensa de la nación. Durante los años cuarenta del siglo XIX, la Guardia Nacional gozó de popularidad porque exentaba a quien estaba inscrito en ella del servicio regular del ejército y no establecía discriminación censitaria. Registrarse en la Guardia Nacional devino un deber de todo mexicano entre la edad de 18 y 50 años; incluso el estar alistado implicaba una extensión en la esfera de derechos: por el hecho de inscribirse en a ella para la defensa de la patria, los individuos adquirían el voto activo y pasivo en las elecciones populares. Quien no formara parte de la Guardia Nacional se exponía a sufrir la pérdida de

\footnotetext{
${ }^{9}$ Hernández Chávez, Alicia, Las fuerzas armadas mexicanas: su función en el montaje de la República, México, El Colegio de México, 2012, p. 31.

${ }^{10}$ Ibidem, p. 34.
} 
sus derechos políticos. ${ }^{11}$

Una vez acordada la amnistía después de la guerra con los Estados Unidos, el poder ejecutivo procedió a federalizar la Guardia Nacional con el fin de acotar los poderes locales y fortalecer el poder central. Los gobiernos estatales levantaron las listas de la Guardia Nacional donde se consideraron novedades: se estableció que la justicia de la Guardia Nacional es inherente a las formas republicanas y el sostén de las libertades públicas; se fijó entonces, un criterio universal de edad entre 16 y 50 años. Más importante aún fue que se concedieron derechos de ciudadanía a quienes prestaran servicio; incluso, en algunos casos, se prometió dotación de tierras al retorno del servicio y restitución de tierras a los pueblos. ${ }^{12}$

$\mathrm{Al}$ respecto cabe hacer mención que "La Guardia Nacional se concibió en los círculos liberales como el instrumento para defender de enemigos internos y externos al sistema federal. El objetivo de la Guardia Nacional era sostener las instituciones democráticas, es decir, el sistema representativo restaurado en 1846. Significó además, el uso de la fuerza pública con la que cada uno de los estados contaba para que los ciudadanos pudieran colaborar en la defensa del país y, así, contribuir en la conservación del orden público. Con ello, no se pretendía que las entidades adquirieran un ejército particular, sino que cada estado contara con elementos de fuerza militar que garantizaran mantener el orden a nivel local. Los padrones de ciudadanos aptos para ser miembros de la Guardia Nacional se hicieron con base en un determinado perfil: el ciu-

11 Cárdenas Gracia, Jaime, "La iniciativa de reforma constitucional que propone la Guardia Nacional. Hechos y Derechos, [S.l.], enero 2019. ISSN 2448-4725, disponible en: https://revistas.juridicas.unam.mx/index.php/hechos-y-derechos/article/ view/13081/14574, [consultado el 5 de junio de 2019].

${ }^{12}$ Hernández Chávez, Alicia, Las fuerzas armadas mexicanas: su función en el montaje de la República, op. cit., p. 38. 
dadano de entre 16 y 50 años que contara con un nivel de ingreso anual, que sabía leer y escribir, y que no formaba parte del ejército.”13

Fueron las coyunturas históricas las que consolidaron a la Guardia Nacional. La primera etapa fue la de la invasión norteamericana entre 1847-1848; la segunda se produjo en 1855 cuando los liberales defienden la desamortización de bienes de las corporaciones, la separación Iglesia-Estado, los derechos individuales y la abolición de fueros y privilegios. Un tercer momento fundamental se da cuando defienden a la república contra el Imperio de Maximiliano. Finalmente, la Guardia Nacional respaldó en 1876 a Porfirio Díaz y su Plan de Tuxtepec. ${ }^{14}$ En julio de 1848, el presidente José Joaquín Herrera promulgó la Ley Orgánica de la Guardia Nacional, a efecto de "Defender la Independencia de la nación, sostener las instituciones, conservar la tranquilidad pública y hacer obedecer las leyes y a las autoridades establecidas por ellas. ${ }^{15}$ También la contempló el Estatuto Orgánico Provisional de la República Mexicana, de 1856, y la Constitución de 1857 la conservó. Con el presidente Juárez no tuvo un mayor cambio. ${ }^{16}$

En 1879 se puso fin a la institución como resultado del proceso de centralización del poder que se inició con la República Restaurada.

${ }^{13}$ Solano González, Jesús, "La Guardia Nacional”, Aida. Ópera Prima de Derecho Administrativo. Revista de la Asociación Internacional de Derecho Administrativo, México, año 6, Opus No. 12, julio-diciembre 2012, p. 210.

${ }^{14}$ Cárdenas Gracia, Jaime, "La iniciativa de reforma constitucional que propone la Guardia Nacional. Hechos y Derechos, [S.l.], enero 2019, disponible en: https://revistas. juridicas.unam.mx/index.php/hechos-y-derechos/article/view/13081/14574, consultado el 27 de mayo de 2019.

${ }^{15}$ Pacheco, Bulmaro, "La Guardia Nacional en México: ¿Qué fue, es y será?, Tribuna, México, 201, disponible en: http://www.tribuna.como.mx/opinion/La-Guardia-Nacional-en-Mexico-Que-fue-es-y-sera-I-20190121-(0004.html, consultado el 05 de junio de 2019.

16 Ídem. 
La figura del ciudadano encuadrado en una fuerza armada, inevitablemente ligada a las disputas políticas locales y nacionales, representó un peligro para la autoridad central. Hay que recordar que, entre la aparición de las Guardias Nacionales y la promulgación de la Constitución de 1857, hubo en México al menos 40 pronunciamientos y rebeliones. ${ }^{17}$

Con Porfirio Díaz, la Guardia Nacional fue absorbida por el ejército federal, nulificando su autonomía. No pocos autores reconocen que la Revolución Mexicana se hizo con una Guardia Nacional, para repeler al ejército porfirista. Más allá de los conflictos internos, la última incursión guerrera por parte de una nación extranjera (EUA) la padecimos en 1914, por Veracruz. Eran los tiempos de Victoriano Huerta. ${ }^{18}$

Aunque la Guardia Nacional existe en diversos preceptos de la Constitución de 1917, durante el siglo XX no operó. En el gobierno del general Cárdenas se pretendió que milicias locales constituyeran la Guardia Nacional. El ex procurador Ignacio Morales Lechuga la promovió para hacer frente a la criminalidad del país. El ex diputado Alberto López Rosas en 1988, la propuso para que se encargara de la protección civil. Los movimientos de autodefensa que han surgido en el país -fundamentalmente en Michoacán y Guerrero-durante el sexenio de Enrique Peña Nieto expresan que las nociones de Guardia Nacional de carácter social - diferente al sentido de la iniciativa de reforma constitucional- no han sido olvidadas en el imaginario social. ${ }^{19}$

En la experiencia histórica internacional, destaca el ejemplo de la Gendarmería Nacional de Francia, un cuerpo de origen medieval pero que en su carácter moderno apareció en 1791 como un cuerpo militar en

${ }^{17}$ Meyer, Lorenzo, "Un híbrido con historia”, op. cit. nota 8

18 Ídem.

${ }^{19}$ Cárdenas Gracia, Jaime, "La iniciativa de reforma constitucional que propone la Guardia Nacional. Hechos y Derechos, op. cit. nota 14 
tareas de policía, básicamente para dar seguridad al mundo rural. Hoy, la Gendarmería es parte del ejército francés, pero adscrita al Ministerio del Interior y ha servido de modelo, entre otras, a las policías militarizadas de España e Italia. ${ }^{20}$

La Guardia Civil española, fundada en 1844, fue la primera fuerza de seguridad pública nacional y fue producto de una emergencia: el bandolerismo rampante en los caminos. Sus efectivos hoy se definen como “militares de profesión y servidores públicos por vocación”. Al ser militarizada, la Guardia tiene una doble adscripción: al Ministerio del Interior y al de Defensa. Por su parte, los carabineros italianos surgieron en 1814 y son la cuarta arma del ejército, pero en su papel de policías nacionales dependen del Ministerio del Interior y desde el año 2000 tienen el carácter de cuerpo autónomo. Entre sus misiones está el apoyar a las policías locales para dar seguridad a la población civil. ${ }^{21}$

\section{DISEÑO INSTITUCIONALDE LA GUARDIA NACIONAL}

La actual administración federal reconoce la inseguridad como una de las principales preocupaciones y amenazas al Estado. Para enfrentar este malestar público, el 14 de noviembre de 2018 se presentó el Plan Nacional de Paz y Seguridad 2018-2024, por parte del entonces Presidente Electo Lic. Andrés Manuel López Obrador, en donde se reconoce la crisis de inseguridad y violencia que vive el país, lo cual hace imposible la consecución del bienestar y la justicia; aspectos sin los cuales no puede conseguirse la paz social. ${ }^{22}$

${ }^{20}$ Meyer, Lorenzo, "Un híbrido con historia”, op. cit, nota 8.

21 Ídem.

${ }^{22}$ Moreno Pérez, Salvador, La Guardia Nacional. ¿Militarización del país o solución a la inseguridad pública?, México, Centro de Estudios Sociales y de Opinión Pública de la Cámara de Diputados del H. Congreso de la Unión, 2019, pp. 13-14. 
Derivado de lo anterior, el actual titular del Poder Ejecutivo Federal propuso ocho ejes de actuación:

1. Erradicar la corrupción y reactivar la procuración de justicia.

2. Garantizar empleo, educación y bienestar.

3. Pleno respeto y promoción de los derechos humanos.

4. Regeneración de la ética social.

5. Reformular el combate a las drogas.

6. Emprender la construcción de la paz.

7. Recuperación y dignificación de las cárceles.

8. Seguridad pública, seguridad nacional y paz. ${ }^{23}$

En el diagnóstico sobre la relación entre la Seguridad Pública y las Fuerzas Armadas de nuestro país, el Ejecutivo federal subraya la lealtad de las mismas hacia al poder civil y lo califica como una singularidad histórica en América Latina. Para el titular del Ejecutivo, el Ejército y la Marina han experimentado procesos de desgaste y de pérdida de confianza entre la población, pero a su criterio, tal cosa se ha debido a órdenes del mando civil para realizar acciones represivas o para participar en tareas de combate a la delincuencia que le son ajenas. Al tiempo que los soldados y marinos no han sido entrenados ni debidamente facultados para prevenir e investigar delitos y debido a esa falta de correspondencia entre preparación y atribuciones se han presentado violaciones a los derechos humanos y atropellos a la población. ${ }^{24}$

${ }^{23}$ López Obrador, Andrés Manuel, Plan Nacional de Paz y Seguridad 2018-2024, México, 2018, p. 13, consultable en https: //lopezobrador.org.mx/wp-content/ uploads/2018/11/Plan-Nacional-de-Paz-y-Seguridad.pdf, [consultado el 03 de junio de 2019].

${ }^{24}$ Ídem. 
En la justificación del actual jefe de la Administración Pública Federal, al involucrarse a las Fuerzas Armadas en el combate a la delincuencia, se argumentó que esta medida sería temporal en tanto se lograba el saneamiento, la capacitación y la profesionalización de las corporaciones policiales. Sin embargo, se asevera que para 2019 las fuerzas civiles se encuentran tan incapacitadas para cumplir su tarea de prevenir y combatir el delito como en 2006. ${ }^{25} \mathrm{El}$ instrumento de planeación dado a conocer por el titular del Ejecutivo presenta diversos objetivos, agrupados en tres vertientes: a) repensar la seguridad nacional y reorientar el papel de las Fuerzas Armadas; b) crear una Guardia Nacional; y c) establecer Coordinaciones Regionales.

En el ámbito legislativo, el 20 de noviembre del año 2018, legisladores del grupo parlamentario del partido MORENA en la Cámara de Diputados presentaron la correspondiente iniciativa de reforma a los artículos 13, 16, 21, 32, 55, 73, 76, 82, 89 y 123 de la Constitución Política de los Estados Unidos Mexicanos. ${ }^{26}$

La Mesa Directiva de la Cámara de Diputados turnó dicha iniciativa a la Comisión de Puntos Constitucionales, instancia que el 20 de diciembre de 2018 aprobó el dictamen respectivo y lo envió a la Cámara revisora el 16 de enero de 2019.

Los rasgos principales de la propuesta fueron, entre otros, los siguientes:

1. La federación contará con una institución policial de carácter y dirección civiles denominada Guardia Nacional, responsable de las tareas de seguridad para la salvaguarda de la vida, la libertad, la integridad y el patrimonio de las personas y la preservación de los bienes y recursos de la nación.

\footnotetext{
${ }^{25}$ Ídem.

${ }^{26}$ González Rodríguez, José de Jesús, Guardia Nacional en México. Carpeta Informativa, México, Centro de Estudios Sociales y de Opinión Pública de la Cámara de Diputados del H. Congreso de la Unión, 2019, p. 7.
} 
2. La estructura orgánica de la Guardia Nacional estará adscrita a la secretaría del ramo de seguridad, y tendría una Junta de Jefes de Estado Mayor compuesta por integrantes de las dependencias de los ramos de Seguridad, de Defensa Nacional y de Marina.

3. La dependencia del ramo de seguridad formulará el programa nacional en la materia y los programas operativos, políticas, estrategias y acciones. En tanto, la Secretaría de la Defensa Nacional dispondría lo necesario para que la estructura jerárquica, la disciplina, el régimen de servicios, los ascensos, las prestaciones, el ingreso, la profesionalización y el cumplimiento de las responsabilidades y las tareas de la Guardia Nacional se homologuen a los que se aplican en las Fuerzas Armadas.

4. Los detenidos deberán ser puestos a disposición en instalaciones de las autoridades civiles.

5. Las instituciones de seguridad pública, incluyendo la Guardia Nacional, serán de carácter civil.

6. La investigación de los delitos corresponde al Ministerio Público, a las policías y a la Guardia Nacional; éstas dos últimas actuarán bajo la conducción jurídica de la representación social.

7. La seguridad pública es una función a cargo tanto de la federación, a través de las instituciones que para tal efecto dispone la Constitución, como de las entidades federativas y de los municipios, en el ámbito de sus respectivas jurisdicciones.

8. El Ministerio Público, la Guardia Nacional y las instituciones policiales deberán coordinarse entre sí para cumplir los objetivos de la seguridad pública y conformarán el Sistema Nacional de Seguridad Pública, al que las entidades federativas y los municipios, a través de sus órganos de policía, deberán suministrar la información de que dispongan en la materia.

9. En tiempo de paz ningún extranjero podrá servir en la Guardia Nacional. 
10. Para tener un cargo de representación se requiere no estar en servicio activo en la Guardia Nacional.

11. El Congreso tendrá la facultad para expedir las leyes sobre la organización, disciplina, profesionalización, operación y evaluación de la Guardia Nacional, así como para expedir la Ley General del Uso Legítimo de la Fuerza y la Ley Nacional del Registro de Detenidos.

12. Será facultad del Senado analizar el informe que el presidente de la república presente sobre las actividades de la Guardia Nacional.

13. Los miembros del Ejército, Fuerza Aérea, Armada y Guardia Nacional se regirán por sus propias leyes.

14. El Estado proporcionará a los miembros en activo de la Fuerza Aérea, Armada y Guardia Nacional las prestaciones laborales respectivas.

El 28 de febrero de 2019, la Cámara de Diputados aprobó con 463 votos a favor y uno en contra el proyecto de decreto que crea la Guardia Nacional, devuelto por el Senado de la República para los efectos de la fracción e) del artículo 72 de la Carta Magna y lo remitió a los congresos estatales para sus efectos constitucionales. El documento reforma, adiciona y deroga diversas disposiciones de los artículos 10, 16, 21, 31, 35, 36, 73, 76,78 y 89 de la Constitución Política. ${ }^{27}$

Al fundamentar el dictamen, la diputada Miroslava Carrillo Martínez (Morena), presidenta de la Comisión de Puntos Constitucionales, dijo que la Guardia Nacional será de carácter civil, tendrá su propia estructura orgánica y organizacional, y una ley que homologue en lo conducente

\footnotetext{
${ }^{27}$ Cámara de Diputados del H. Congreso de la Unión, Aprueba Cámara de Diputados reforma constitucional que crea la Guardia Nacional; la remite a congresos locales, Boletín Número 1157, 28 de febrero de 2019, disponible en http: //www5.diputados.gob.mx/index. php/esl/Comunicacion/Boletines/2019/Febrero/28/1157-Aprueba-Camara-de-Diputados-reforma-constitucional-que-crea-la-Guardia-Nacional-la-remite-a-congresos-locales, [consultado el 03 de junio de 2019].
} 
las disposiciones de las fuerzas armadas. ${ }^{28}$

El coordinador de la bancada del Partido Acción Nacional, el diputado Juan Carlos Romero Hicks, puntualizó que esta minuta establece un mando civil, actuación temporal de las fuerzas armadas, controles institucionales con actuación del Congreso, fortalecimiento de las diversas policías, un espíritu más federalista, así como un mínimo de leyes secundarias -del Sistema Nacional de Seguridad Pública, de la Guardia Nacional, Nacional del Uso de la Fuerza y Nacional de Registro de Detenciones-. Lamentó que no se haya modificado el término para llamarle Guardia Civil y no Guardia Nacional, y no hubiere confusión; sin embargo, dijo, la tarea legislativa no termina aquí; es necesario fortalecer los fondos públicos y sobre todo la construcción de las leyes secundarias. "El país no quiere violencia, inseguridad, corrupción ni impunidad. Necesitamos construir y entender que la pluralidad es una divisa y no un mal tolerado". ${ }^{29}$

A nombre del Partido Revolucionario Institucional, el diputado René Juárez Cisneros sostuvo que para garantizar la seguridad de los mexicanos no debe haber mezquindades y no caben límites partidarios. Resaltó la responsabilidad para discutir y aprobar por consenso en el Congreso la Guardia Nacional, que será instrumento fundamental para enfrentar el flagelo de la inseguridad. Hizo votos porque se avance también en combatir la corrupción e impunidad. Refirió un acuerdo razonable, tal vez no suficiente, pero permitió avanzar en una Guardia Nacional con vocación y mando civil que respete los derechos humanos, soberanía y federalismo y fortalezca los cuerpos policiacos estatales y municipales. Celebró la definición de un marco legal temporal para que las fuerzas armadas ten-

\footnotetext{
${ }^{28}$ Ídem.

29 Ídem.
} 
gan certeza y certidumbre en el despliegue de sus tareas y en cinco años regresen a sus cuarteles. ${ }^{30}$ Posteriormente, el día 26 de marzo de 2019 se publicó en el Diario Oficial de la Federación el "Decreto por el que se reforman, adicionan y derogan diversas disposiciones de la Constitución Política de los Estados Unidos Mexicanos en materia Guardia Nacional.

En este sentido, cabe hacer notar la expresión de distintos organismos, tanto de gobierno como de la sociedad civil, en relación con la creación o evolución de esta figura para hacer frente a la crisis de seguridad por la que actualmente, y desde hace al menos una década, atraviesa el Estado mexicano. Diversos líderes de opinión, organizaciones de la sociedad civil y usuarios de redes sociales entre quienes destacaron más de 300 colectivos y organizaciones, como el Centro Nacional de Comunicación Social (Cencos) y Artículo 19, entre otras, rechazaron la aprobación de la Guardia Nacional considerando que su conformación es una continuación de las estrategias castrenses de gobiernos anteriores, que resultaron fallidas para combatir el incremento del crimen organizado. ${ }^{31}$ De acuerdo con su postura, "resulta peligrosísimo para cualquier democracia permitir que toda la capacidad bélica y de fuerza, la mayoría de tu inteligencia y la mayoría de tus elementos de fuerza, queden bajo el mando una secretaría y de una institución. Toda democracia saludable requiere pesos y contrapesos, especialmente en el marco del uso de la fuerza”. ${ }^{32}$

30 Ídem.

${ }^{31}$ González Rodríguez, José de Jesús, Guardia Nacional en México. Carpeta Informativa, op. cit., p. 69.

32 Salazar, Ana María, "Guardia Nacional: amenaza a la democracia y las Fuerzas Armadas”, El Financiero, México, 21 de noviembre de 2018, https:/www.elfinanciero.com.mx/opinion/ana-maria-salazar/guardia-nacional-amenaza-a-la-democracia-y-las-fuerzas-armadas. 
"Se puede argumentar que, en la coyuntura actual, el éxito o fracaso de una Guardia Nacional no está ligado a su naturaleza -un híbrido militar y civil-, sino a la del gobierno, del proyecto del que será parte y a la calidad de los mandos. Así, la apuesta del Presidente, descansa en el hecho de que él, personalmente, será el que demande, diariamente, la rendición de cuentas a los mandos de la Guardia Nacional en el empeño por recuperar la elusiva paz que tanto necesitamos como comunidad nacional”. 33

Uno de los temas que más controversia generó fue el de la naturaleza del mando de la Guardia Nacional. La movilización social se circunscribió en que ante su inminente aprobación, la misma estuviera en manos de un civil, en despropósito de la iniciativa aprobada por la Cámara de Diputados, que planteaba otorgar el mismo a un militar en activo. Esta iniciativa, fue enviada al Senado de la República para continuar con el proceso legislativo, cuyo proyecto de decreto fue modificado en lo que refiere al mando militar; estableciendo que la Guardia Nacional tendría mando civil, con una temporalidad de cinco años de participación de las fuerzas armadas. Es así que, luego del consenso de las fuerzas políticas en el Senado, el 21 de febrero de 2019, la Cámara Alta aprobó por unanimidad el dictamen modificado que da lugar a la creación de la Guardia Nacional; responsable de las tareas de seguridad pública de carácter civil. Dicho dictamen estableció la facultad del Ejecutivo Federal para designar al titular del órgano de mando superior y a los integrantes de la instancia de coordinación operativa interinstitucional formada por representantes de las secretarías del ramo de Seguridad, Defensa Nacional y de Marina. Asimismo, se estableció que, durante los cinco años siguientes a la entrada en vigor del Decreto, en tanto la Guardia Nacional desarrolla

${ }^{33}$ Meyer, Lorenzo, "Un híbrido con historia”, op. cit. 
su estructura, capacidades e implantación territorial, el Presidente de la República podrá disponer de la Fuerza Armada permanente en tareas de seguridad pública de manera extraordinaria, regulada, fiscalizada, subordinada y complementaria.

El dictamen también estableció el deber del Congreso de la Unión de realizar reformas a la Ley General del Sistema Nacional de Seguridad Pública, y expedir la Ley de la Guardia Nacional, la Ley Nacional sobre el Uso de la Fuerza y la Ley Nacional del Registro de Detenciones. ${ }^{34}$ Aprobada la reforma constitucional por el Congreso de la Unión, fue enviada a las 32 entidades para su aprobación, a fin de completar el proceso de reforma constitucional, mismo que fue respaldado de manera unánime, por lo que dicha reforma fue remitida al Ejecutivo para su publicación, mismo que fue publicado en el Diario Oficial de la Federación el 26 de marzo de 2019. ${ }^{35}$

Posteriormente, el 21 de mayo de 2019, el Senado de la República aprobó los cuatro dictámenes de las leyes reglamentarias de la Guardia Nacional, en los cuales se establecen sus funciones y objetivos, la protección de los derechos humanos y regulan el uso de la fuerza. Este bloque de leyes secundarias está compuesto por: a) Ley de la Guardia Nacional; b) Ley Nacional sobre el uso de la fuerza; c) Ley Nacional del Registro de Detenciones y; d) Ley General del Sistema Nacional de Seguridad Pública. Los cuatro documentos fueron remitidos por la Mesa Directiva a la Cámara de Diputados, quienes lo aprobaron sin ninguna modificación

${ }^{34}$ Boletín del Senado por el que se da a conocer la aprobación de la Guardia Nacional, Visible en: http://comunicacion.senado.gob.mx/index.php/informacion/boletines/43818-por-unanimidad-aprueban-la-guardia-nacional.html [consultado el 5 junio de 2019]

${ }^{35}$ Diario Oficial de la Federación: https://www.dof.gob.mx/nota_detalle.php?codigo $=5555126 \&$ fecha $=26 / 03 / 2019$

[Consultado el 9 de junio de 2019] 
el 23 de mayo de la misma anualidad. Fue publicada en el Diario Oficial de la Federación el 27 de mayo de 2019. ${ }^{36}$

De los puntos relevantes de los nuevos ordenamientos se destaca lo siguiente:

1. La Guardia Nacional es una institución policial, armada, civil, disciplinada, profesional y permanente, con autonomía técnica, operativa y de mando. Su naturaleza jurídica es de un órgano administrativo desconcentrado adscrito a la Secretaría de Seguridad y Protección Ciudadana cuyo titular ejercerá el mando originario. ${ }^{37}$

2. Ahora, si bien, la reforma constitucional que crea la Guardia Nacional, estableció que la misma tendría un mando civil, la Ley de la Guardia Nacional establece en el título sexto que la Coordinación Operativa institucional estará integrada por la Secretaría de Seguridad y Protección Ciudadana, Secretaría de la Defensa Nacional y la Secretaría de Marina, de lo cual se colige que tendrá dos mandos militares y uno civil. (Art. 86 de la ley). ${ }^{38}$

3. En cuanto a su estructura, el 13 de la ley señala que la Guardia Nacional tendrá los siguientes niveles de mando: secretario; comandante; coordinador territorial; coordinador estatal y coordinador de unidad. Además, el artículo 21 de la ley en cita prevé que, dentro de la estructura orgánica de la Guardia Nacional, el primer nivel jerárquico estará comprendido por un Comandante, quien de acuerdo

${ }^{36}$ Boletín de la Cámara de Diputados por el que se da conocer la aprobación de Leyes de la Guardia Nacional Disponible: http://www5.diputados.gob.mx/index.php/esl/ Comunicacion/Boletines/2019/Mayo/23/1698-La-Camara-de-Diputados-aprobo-cuatro-leyes-reglamentarias-de-la-Guardia-Nacional-las-remitio-al-Ejecutivo

${ }^{37}$ Boletín por el que el Senado da a conocer la aprobación de las leyes secundarias en materia de la Guardia Nacional. Disponible en: http://comunicacion.senado.gob. $\mathrm{mx}$ /index.php/informacion/boletines/44905-aprueban-leyes-reglamentarias-de-la-guardia-nacional.html [consultado el 10 de junio de 2019].

${ }^{38}$ Diario Oficial de la federación Disponible en: https://www.dof.gob.mx/nota_detalle.php?codigo=5561285\&fecha=27/05/2019 
con el artículo 14 será nombrado por el presidente de la República. El Gobierno federal anunció que la comandancia de la Guardia Nacional quedará el general de brigada diplomado del Estado Mayor en proceso de retiro, Luis Rodríguez Bucio.

En este sentido, los análisis sobre su idoneidad también se han manifestado en relación sobre la naturaleza de su función: es un correctivo para combatir la inseguridad o es un mecanismo de contención en lo que se define e implementa una nueva política de seguridad y se fortalecen las distintas corporaciones de seguridad que ejercen sus funciones en México. Al respecto, el Doctor Raúl Contreras Bustamante publicó recientemente unos datos que nos invitan a considerar la figura más como un elemento de una política integral que debe generarse para hacer frente a esta problemática. De acuerdo con él, "se prevé que para finales de año, los guardias de este cuerpo de seguridad alcancen los 80 mil elementos. El número puede parecer impactante, sin embargo, si este número es dividido entre las 32 entidades federativas, se tendrían sólo 2,500 guardias por cada una de ellas, para cubrir los tres turnos, fines de semana y días festivos $\mathrm{Si}$ además se divide el número de guardias entre los 2,457 municipios que el INEGI reporta que existen, corresponderían 32.5 elementos por municipio. De tal suerte que serán claves los criterios mediante el cual serán distribuidos los efectivos a lo largo del territorio nacional". 39

Por otra parte, de conformidad con datos elaborados por Naciones Unidas, el número ideal que debe tener un Estado por cada habitante es de 2.8; sin embargo, en México, "al 31 de enero de 2017, la federación

${ }^{39}$ Contreras Bustamante, Raúl, “La guardia Nacional y sus leyes secundarias”, Columna publicada en Excélsior el 8 de junio de 2019, visible en: https:/www.excelsior. com.mx/opinion/raul-contreras-bustamante/la-guardia-nacional-y-sus-leyes-secundarias/1317427 [consultado el 8 de junio de 2019] 
y las entidades federativas en conjunto registraron sólo un promedio de 0.8 policías por cada mil habitantes. De tal suerte que el país tiene menos de la tercera parte de los policías preventivos que de manera ideal debería tener". En esta tesitura, el reto no solo consiste en hacer efectivo en la práctica la intencionalidad con la que se crea la figura; sino además, debe establecerse una política integral en materia de seguridad y potenciar la funcionalidad y eficacia de los cuerpos policíacos, de tal suerte que la Guardia Nacional sea una institución coadyuvante en las tareas de combate a la inseguridad y no el único cuerpo responsable de garantizar la función primigenia del Estado mexicano.

\section{PERSPECTIVA INTERNACIONAL DE LOS DERECHOS HUMANOS}

Diversas instancias internacionales han manifestado su preocupación en relación con la creación de la Guardia Nacional. Entre ellos, se encuentra la Oficina en México del Alto Comisionado de las Naciones Unidas para los Derechos Humanos, instancia que ha expresado sus cuestionamientos en torno a los siguientes puntos de la iniciativa:

1. Indebida regulación de los alcances del fuero militar.

2. Riesgos en el traslado de personas detenidas.

3. Cuestionamientos a la naturaleza de la detención en flagrancia y el registro de esa detención.

4. Definición y facultades de investigación de la Guardia Nacional.

5. Regulación del uso de la fuerza.

6. Competencia de la Corte Penal Internacional.

7. Fundamentos constitucionales de la seguridad pública.

8. Facultades legislativas del presidente de la república.

9. Regulación de cuestiones sustantivas en los artículos transitorios. 
10. Temporalidad de la reforma constitucional..$^{40}$

Otro de los organismos que ha externado su preocupación en torno a la creación de la Guardia Nacional en México ha sido Amnistía Internacional, quien ha planteado ocho ejes de argumentación para contravenir la iniciativa que da origen a la Guardia Nacional, los cuales se describen a continuación:

1. Excepcionalidad del uso de las Fuerzas Armadas en labores de seguridad pública.

2. Retiro ordenado de las Fuerzas Armadas de labores de seguridad pública.

3. Protección de las personas detenidas y garantías del debido proceso.

4. Necesidad de una Ley de Uso de la Fuerza y una Ley del Registro de Detenciones.

5. Mecanismos de supervisión y evaluación de la Guardia Nacional.

6. Jurisdicción Militar.

7. Jurisdicción de la Corte Penal Internacional.

8. Fortalecimiento de las policías civiles. ${ }^{41}$

Para la organización Human Rights Watch, el Congreso mexicano debió rechazar el proyecto de reforma constitucional que crearía la Guardia Nacional en atención a las siguientes razones:

${ }^{40}$ Análisis preliminar de la Oficina en México del Alto Comisionado de las Naciones Unidas para los Derechos Humanos (ONU-DH) sobre el Proyecto de Dictamen de la Comisión de Puntos Constitucionales de la Cámara de Diputados sobre la iniciativa con Proyecto de Decreto que reforma diversos artículos de la Constitución Política de los Estados Unidos Mexicanos en materia de Guardia Nacional, ONU-DH diciembre 2018, disponible en: https://www.hchr.org.mx/images/doc_pub/ONU_DH_DocumentoT\%C3\%A9cnico_Guardia_Nacional.pdf [Consultado el 30 de mayo de 2019].

${ }^{41}$ Amnistía Internacional, México: Guardia Nacional. Obligaciones internacionales de Derechos Humanos, Amnistía Internacional, Reino Unido, 2019, pp. 1-6, disponible en: https:/www.amnesty.org/download/Documents/AMR4196972019SPANISH.PDF [consultado el 31 de mayo de 2019]. 
1. La militarización de la Seguridad Pública ha resultado en violaciones generalizadas de Derechos Humanos en México y no ha mejorado ésta.

2. La pretensión de ampliar la prisión preventiva exigiría que los jueces dispongan la detención de toda aquella persona investigada por un amplio espectro de delitos y eso incrementaría la cantidad de personas en las cárceles mexicanas a las que no se les ha dictado sentencia.

3. Se debe fortalecer a la policía civil y al sistema de justicia, en vez de redoblar la política de militarizar la Seguridad Pública, situación que ha demostrado ser un fracaso total.

4. Las Fuerzas Armadas han cometido gravísimos abusos contra civiles, con generalizada impunidad y es posible que haya sido un factor que contribuyó al drástico aumento en la cantidad de homicidios en estos años. ${ }^{42}$

Por otra parte, en su Informe de actividades del 1 de enero al 31 de diciembre de 2018, la Comisión Nacional de los Derechos Humanos puntualizó sus inquietudes respecto a la propuesta del Presidente López Obrador para crear la Guardia Nacional, lo cual hizo en los términos siguientes:

1. La posible participación de las Fuerzas Armadas en tiempos de paz se encuentra necesariamente constreñida a condiciones eventuales y transitorias, y que está sujeta, en todo momento, al mando de las autoridades civiles.

2. La participación de las Fuerzas Armadas en tareas de Seguridad Pública no es lo más adecuado, dada la especial naturaleza de sus funciones constitucionales, pues su entrenamiento está dirigido a derrotar un objetivo legítimo y no a la protección y control de civiles, que es propio de los entes policiales, por lo que el uso de las Fuerzas

\footnotetext{
${ }^{42}$ Human Rights Watch, "México debe rechazar reforma que militariza la Seguridad Pública”, HRW, EEUU, 2019, disponible en: https://www.hrw.org/es/ news/2019/01/14/mexico-debe-rechazar-reforma-que-militariza-la-seguridad-publica [consultado el 31 de mayo de 2019].
} 
Armadas no es la vía de acción idónea para garantizar los Derechos Humanos.

3. La Guardia Nacional, al estar mayoritariamente conformada por elementos de las Fuerzas Armadas, contraviene lo previsto por los principios que ha sustentado la Constitución, en el sentido de garantizar la primacía y la división de las autoridades civiles sobre las militares, siendo contraria, de igual forma, a recomendaciones y criterios formulados por instancias internacionales en materia de Derechos Humanos.

4. Deben ser las autoridades civiles las encargadas de las tareas vinculadas a la Seguridad Pública, reduciéndose al mínimo la intervención de las Fuerzas Armadas. ${ }^{43}$

En el marco de sesiones de la Corte Interamericana de Derechos Humanos, celebradas del 3 al 7 de diciembre de 2017, referente a la militarización de la seguridad pública en países de América, la Corte Interamericana de Derechos Humanos reconoció los retos actuales relacionados con la tendencia a la militarización actual en países como México, en el que se pretende la intervención directa de las fuerzas armadas en tareas de seguridad.

En relación con el caso "Atenco", en 2015, la Comisión Interamericana concluyó que el Estado mexicano es responsable por la violación de los derechos a la integridad personal; a la libertad personal; a la vida privada, dignidad y autonomía; a las garantías judiciales; al derecho a la igualdad y no discriminación; y a la protección judicial, establecidos en los artículos 5, 7, 8, 11, 24 y 25 de la Convención Americana, en relación con las obligaciones establecidas en el artículo 1.1 del mismo instrumento,

\footnotetext{
${ }^{43}$ Comisión Nacional de Derechos Humanos, "Informe de actividades del 1 de enero al 31 de diciembre de 2018”, CNDH, México, 2019, disponible en: http:/informe. cndh.org.mx/uploads/principal/2018/IA_2018.pdf, [consultado el 01 de junio del 2019].
} 
en perjuicio de las personas que se indican en cada una de las secciones del presente informe. Asimismo, la Comisión concluyó que el Estado mexicano es responsable por la violación de los artículos 1, 6 y 8 de la Convención Interamericana para Prevenir y Sancionar la Tortura (en adelante "la CIPST") y del artículo 7 de la Convención para Prevenir, Sancionar y Erradicar la Violencia contra la Mujer.

Entre las recomendaciones de la Comisión figura que el Estado mexicano deberá adoptar medidas de no repetición dirigidas a capacitar a los cuerpos de seguridad tanto a nivel federal como estatal en la prohibición absoluta de la tortura y de la violencia sexual y de otra índole contra la mujer, así como a enviar un claro mensaje de repudio a este tipo de actos.

De acuerdo con un extracto de la sentencia de la Corte Interamericana de Derechos Humanos, se determinó lo siguiente:

“(...) Como la Corte constató en el capítulo IX-1 de esta Sentencia, el uso ilegítimo y excesivo de la fuerza por parte del Estado en el contexto de los hechos acaecidos el 3 y 4 de mayo de 2006 en Texcoco y San Salvador de Atenco conllevó violaciones a distintos derechos consagrados en la Convención. Este Tribunal valora de manera positiva los esfuerzos llevados a cabo por el Estado, tanto a nivel federal como estadual para establecer límites al uso de la fuerza en contextos de protesta social y para fiscalizar a los cuerpos de policía. Sin embargo, estima pertinente ordenar al Estado la creación e implementación, en el plazo de dos años, de un plan de capacitación de oficiales de la Policía Federal y del Estado de México orientado a: (i) sensibilizar a los miembros de los cuerpos de policía en abordar con perspectiva de género los operativos policiales, el carácter discriminatorio de los estereotipos de género como los empleados en este caso y el absoluto deber de respeto y protección de la población civil con la que entran en contacto en el marco de sus labores orden público, así como a (ii) capacitar a los agentes de policía sobre los 
estándares en materia del uso de la fuerza en contextos de protesta social establecidos en esta Sentencia y en la jurisprudencia de esta Corte. Este plan de capacitación debe ser incorporado en el curso de formación regular de los miembros del cuerpo de policía federal y estadual.

De igual manera, la Corte dispone que el Estado deberá establecer al nivel federal un observatorio independiente que permita dar seguimiento a la implementación de las políticas en materia de rendición de cuentas y monitoreo del uso de la fuerza de la Policía Federal y la policía del estado de México, dentro del cual se permita la participación de miembros de la sociedad civil. Asimismo, dicho observatorio deberá generar información que permita realizar mejoras institucionales en la materia. Para tales efectos, el Estado deberá generar sistemas de información que permitan: (i) evaluar la efectividad de los mecanismos existentes de supervisión y fiscalización de los operativos policiales antes, durante y después del uso de la fuerza, y (ii) brindar retroalimentación sobre las mejoras institucionales que correspondan de acuerdo con la información obtenida por medio del observatorio. Para el cumplimiento de esta medida el Estado deberá acreditar la creación del observatorio, con las características especificadas, así como su puesta en funcionamiento. Sin embargo, la Corte no supervisará su implementación. En este sentido, el Tribunal manifestó que en el Caso Montero Aranguren y otros Vs. Venezuela estableció que si bien los Estados partes de la Convención podrían desplegar a las fuerzas armadas para desempeñar tareas ajenas a las propiamente relacionadas con conflictos armados, dicho empleo debe limitarse al máximo y responder a criterios de estricta excepcionalidad para enfrentar situaciones de criminalidad o violencia interna, dado que el entrenamiento que reciben las fuerzas militares está dirigido a derrotar al enemigo y no a la protección y control de civiles, entrenamiento que 
es propio de los entes policiales”. ${ }^{44}$

En este sentido, es necesario resaltar que México, al haber sido condenado por la Corte Interamericana, tiene obligaciones de ejecución, pero también de adoptar medidas para evitar la repetición de este tipo de incidentes; es decir, la política en materia de seguridad debe estar encaminada a fortalecer y enriquecer mediante perspectiva de género, delimitación clara de ejercicio de la fuerza como ultima ratio y capacitación constante a los cuerpos de seguridad, más que en la creación de nuevas corporaciones para hacer frente a la problemática de la inseguridad. No se debe dejar del lado esta sentencia, así como los lineamientos en materia de control de la ejecución de las mismas, a cargo de organismos de la sociedad civil, pues ello es fundamental para cuadrar la legislación nacional y la articulación de la política en materia de seguridad, de acuerdo con los cánones y postulados vigentes en la Convención Americana de los Derechos Humanos.

\section{CONCLUSIONES}

Primera.- La Guardia Nacional como institución responsable de garantizar la seguridad interior data desde tiempos remotos en la historia constitucional mexicana. Se creó bajo la misma idea que se concibió en el diseño de la Federación mexicana, con base en la unión de Estados soberanos que decidieron agruparse en una entidad mayor con el propósito de garantizar su seguridad y proteger los intereses de sus ciudadanos. La noción de 1824 permite distinguir con claridad que en materia de creación de instituciones que busquen tener vigencia a lo largo del territorio nacional, es más óptimo crear desde la particularidad de los esta-

${ }^{44}$ Caso mujeres víctimas de tortura sexual en Atenco vs. México sentencia de 28 de noviembre de 2018, visible en: http://www.corteidh.or.cr/docs/casos/articulos/seriec_371_esp.pdf [consultado el 10 de junio de 2019] 
dos hasta la generalidad de la Federación. El intento inverso complica la manera en que cada estado implementa lo que la Federación diseña bajo la idea de unanimidad y generalidad, por lo que la Guardia Nacional en los términos que se plantea su "nueva creación” o la "evolución” de su diseño institucional, no debe dejar del lado que los detalles finos de su eficacia pasan por cómo se implemente en los estados la ejecución de su creación desde el Gobierno Federal.

Segunda.- El proceso de su aprobación no ha estado exento de manifestación y expresión de ideas en su contra, desde distintos ámbitos de la sociedad civil, así como por parte de organismos de gobierno y observatorios internacionales. Existen sendas dudas sobre la viabilidad de su creación y la eficacia para hacer frente a las problemáticas de seguridad que enfrenta el Estado mexicano. Se considera que no es un diseño viable y corre el riesgo de acrecentar la ola de inseguridad aunado a la posibilidad de trasgredir derechos humanos en el ejercicio de las tareas de seguridad. El desplazamiento de fuerzas del orden militar es inconcebible desde una óptica del Estado constitucional si se entiende como la única alternativa para desarticular las estructuras delictivas y confrontar las organizaciones criminales. Por estas razones fue modificado el dictamen aprobado en la Cámara de Diputados, cuya base era la iniciativa enviada por el Presidente de la República, de cara garantizar que el mando de esta nueva corporación recayera en un civil y no un militar.

Tercera.- Desde la óptica del Sistema Interamericano de Derechos Humanos, México cuenta con antecedentes negativos en lo relativo a condenas por parte de la Corte Interamericana, por violaciones cometidas por distintas corporaciones de seguridad (Ejército, Marina y Policía Federal) en contra de los derechos humanos de sus ciudadanos. Incluso en lo que respecta a la dinámica de ejecución en que estas sentencias 
condenatorias deberán resarcir las violaciones mencionadas, se han delimitados políticas integrales de seguridad tendientes a fortalecer las corporaciones se seguridad, capacitar a sus integrantes y crear observatorios ciudadanos responsables de verificar su cumplimiento en los términos ordenados. Con base en estas consideraciones, la "nueva” Guardia Nacional enfrenta retos mayúsculos no solo en la consecución del fin para el que fue diseñada: garantizar la seguridad del Estado mexicano, sino además, en hacerlo bajo los estándares internacionales de derechos humanos, que forman parte de la Ley Suprema del Estado mexicano, según lo dispuesto por el artículo 133 constitucional y cuidando en todo momento no repetir hechos lamentables que suman en la deslegitimación de los mismos ante la sociedad y el desencanto de la política de confrontación que muy pocos resultados ha generado en tratándose de desarticular al crimen organizado y garantizar la seguridad como bien jurídico tutelado más importante de cualquier Estado Constitucional.

Cuarta.- Desde la perspectiva del diseño institucional se debe poner especial atención a las particularidades mediante las cuales se pretende implementar el desarrollo de la Guardia Nacional. El hecho de que se haya modificado el dictamen para dotarla de un mando civil no fue suficiente para evitar que un militar estuviera a su cargo, ni que los responsables de su coordinación fueran en su mayoría del fuero militar, pues en el artículo 13 de la Ley Reglamentaria se estableció que la Coordinación Operativa estará integrada por la Secretaria de la Defensa Nacional, la Secretaria de Marina y la Secretaria de Seguridad y Protección Ciudadana; es decir, dos mandos militares y uno civil. Asimismo, el artículo 86 establece la facultad para que sea el Presidente de la República quien tenga a su cargo el nombramiento del Comandante que por estructura jerárquica es el de más alto rango en la misma, lo que permitió que 
se eligiera a un militar en activo en proceso de retiro. En este sentido, conviene hacer también hincapié en el hecho de que cada corporación de seguridad, tanto civil como militar, tiene una determinada ideología en el ejercicio de sus funciones. A nivel de capacitación, interlocución y diálogo institucional, hacer converger tres distintas ideologías para coordinarse en materia de seguridad no será tarea fácil ni a nivel directivo, ni en la escala operacional. Ello es uno de los muchos retos que la Guardia Nacional habrá de enfrentar, pues la experiencia mexicana nos ha enseñado que cuando se trata de relaciones de coordinación entre distintos entes los procesos del día a día se complican y en un tema que requiere atención urgente, no es conveniente que por diferencias consustanciales a la naturaleza disímbola de las instituciones involucradas, no se alcancen los objetivos planteados en la justificación de la creación de esta nueva corporación.

Quinta.- Finalmente debemos considerar que la Guardia Nacional no es la panacea para resolver la problemática de inseguridad que aqueja al Estado mexicano. Bajo la lógica que fue propuesta y aprobada se advierte que la administración entrante pretende modificar la ejecución del combate al crimen organizado, pero no se aprecian intenciones relativas a cambiar la política integral en esta materia. Ello debe preocuparnos porque la Guardia Nacional por sí misma no servirá de mucho si a la par de su diseño, creación y ejecución, no se aumenta la cantidad de policías de primera aproximación, se someten a controles de confianza los cuerpos policíacos existentes y se prepara a los mismos de cara a retomar lo que por la naturaleza institucional de su actividad deben llevar a cabo: tareas de seguridad pública. No debemos olvidar que aunque por el tiempo prolongado que hemos visto a las corporaciones militares en las calles, ello no es facultad propia de ellas, sino que la falta de eficacia y alcance de las de naturaleza ci- 
vil, orilló a las primeras a salir de los cuarteles para responder las falencias en las estructuras del Estado. En este sentido, conviene hacer notar que la política en materia de seguridad y combate al crimen organizado debe ser replanteada y orientada a modificar el todo de las estructuras estatales, mas no a crear nuevas corporaciones; depurar las existentes para que las de nueva creación sigan derroteros con base en estándares mínimos de respeto y garantía de derechos humanos; y recordar, que aunado a la legislación nacional y la base constitucional, México está obligado a cumplimentar las sentencias de la Corte Interamericana de Derechos Humanos.

\section{FUENTES}

1. BIBLIOGRAFIA

Amnistía Internacional, México: Guardia Nacional. Obligaciones internacionales de Derechos Humanos, Amnistía Internacional, Reino Unido, 2019, pp. 1-6, disponible en: https://www.amnesty.org/download/Documents/AMR4196972019SPANISH.PDF, consultado el 31 de mayo de 2019.

Human Rights Watch, "México debe rechazar reforma que militariza la Seguridad Pública”, HRW, EEUU, 2019, disponible en: https:/www.hrw.org/es/ news/2019/01/14/mexico-debe-rechazar-reforma-que-militariza-la-seguridad-publica, consultado el 31 de mayo de 2019.

Análisis preliminar de la Oficina en México del Alto Comisionado de las Naciones Unidas para los Derechos Humanos (ONU-DH) sobre el Proyecto de Dictamen de la Comisión de Puntos Constitucionales de la Cámara de Diputados sobre la iniciativa con Proyecto de Decreto que reforma diversos artículos de la Constitución Política de los Estados Unidos Mexicanos en materia de Guardia Nacional, ONU-DH diciembre 2018, disponible en: https:/www.hchr.org.mx/images/doc_pub/ONU_ DH_DocumentoT\%C3\%A9cnico_Guardia_Nacional.pdf consultado a las 13:00 horas del 30 de mayo de 2019. 
Boletín de la Cámara de Diputados por el que se da conocer la aprobación de Leyes de la Guardia Nacional Disponible: http://www5.diputados.gob. mx/index.php/esl/Comunicacion/Boletines/2019/Mayo/23/1698-La-Camara-de-Diputados-aprobo-cuatro-leyes-reglamentarias-de-la-Guardia-Nacional-las-remitio-al-Ejecutivo

Boletín por el que el Senado da a conocer la aprobación de las leyes secundarias en materia de la Guardia Nacional. Disponible en: http://comunicacion.senado.gob.mx/index.php/informacion/boletines/44905-aprueban-leyes-reglamentarias-de-la-guardia-nacional.html [consultado el 10 de junio de 2019].

Cámara de Diputados del H. Congreso de la Unión, Aprueba Cámara de Diputados reforma constitucional que crea la Guardia Nacional; la remite a congresos locales, Boletín Número 1157, 28 de febrero de 2019, disponible en: http:// www5.diputados.gob.mx/index.php/esl/Comunicacion/Boletines/2019/ Febrero/28/1157-Aprueba-Camara-de-Diputados-reforma-constitucional-que-crea-la-Guardia-Nacional-la-remite-a-congresos-locales, consultado el 03 de junio de 2019.

Cárdenas Gracia, Jaime, "La iniciativa de reforma constitucional que propone la Guardia Nacional. Hechos y Derechos, [S.I.], enero 2019. ISSN 2448-4725, disponible en: https://revistas.juridicas.unam.mx/index.php/hechos-y-derechos/article/view/13081/14574, consultado el 05 de junio de 2019.

Caso mujeres víctimas de tortura sexual en Atenco vs. México sentencia de 28 de noviembre de 2018, Visible en: http:/www.corteidh.or.cr/docs/casos/ articulos/seriec_371_esp.pdf [consultado el 10 de junio de 2019]

Comisión Nacional de Derechos Humanos, "Informe de actividades del 1 de enero al 31 de diciembre de 2018”, CNDH, México, 2019, disponible en: http://informe.cndh.org.mx/uploads/principal/2018/IA_2018.pdf, consultado el 01 de junio del 2019 
Contreras Bustamante, Raúl, "La guardia Nacional y sus leyes secundarias”, Columna publicada en Excélsior el 8 de junio de 2019, visible en: https:// www.excelsior.com.mx/opinion/raul-contreras-bustamante/la-guardia-nacional-y-sus-leyes-secundarias/1317427 [consultado el 8 de junio de 2019]

González Rodríguez, José de Jesús, Guardia Nacional en México. Carpeta Informativa, México, Centro de Estudios Sociales y de Opinión Pública de la Cámara de Diputados del H. Congreso de la Unión, 2019.

Hernández Chávez, Alicia, Las fuerzas armadas mexicanas: su función en el montaje de la República, México, El Colegio de México, 2012.

López Obrador, Andrés Manuel, Plan Nacional de Paz y Seguridad 2018-2024, México, 2018, consultable en https://lopezobrador.org.mx/wp-content/ uploads/2018/11/Plan-Nacional-de-Paz-y-Seguridad.pdf, consultado el 03 de junio de 2019.

Meyer, Lorenzo, "Un híbrido con historia”, El Universal, México, 2019, disponible en: https://www.eluniversal.com.mx/columna/lorenzo-meyer/un-hibrido-con-historia, consultado el 26 de mayo de 2019.

Moreno Pérez, Salvador, La Guardia Nacional. ¿Militarización del país o solución a la inseguridad pública?, México, Centro de Estudios Sociales y de Opinión Pública de la Cámara de Diputados del H. Congreso de la Unión, 2019.

Pacheco, Bulmaro, "La Guardia Nacional en México: ¿Qué fue, es y será?, Tribuna, México, 201, disponible en: http://www.tribuna.como.mx/opinion/ La-Guardia-Nacional-en-Mexico-Que-fue-es-y-sera-I-20190121-0004. html, consultado el 05 de junio de 2019.

SAlazAr, Ana María, "Guardia Nacional: amenaza a la democracia y las Fuerzas Armadas”, El Financiero, México, 21 de noviembre de 2018, https://www. elfinanciero.com.mx/opinion/ana-maria-salazar/guardia-nacional-amenaza-a-la-democracia-y-las-fuerzas-armadas. 
Solano González, Jesús, "La Guardia Nacional”, Aida. Ópera Prima de Derecho Administrativo. Revista de la Asociación Internacional de Derecho Administrativo, México, año 6, Opus No. 12, julio-diciembre 2012.

Voz Communicatio in sacris, en "Diccionario General de Derecho Canónico", Pamplona. Visible en: http://www.collationes.org/de-documenta-theologica/iure-canonico/item/371-sobre-la-communicatio-in-sacris-antonio-s-s\%C3\%A1nchez-gil [consultado el 9 de junio de 2019] 